\title{
OPEN Awareness, treatment, control, and determinants of dyslipidemia among adults in China
}

\author{
Sampson Opoku ${ }^{1 凶}$, Yong Gan ${ }^{1}$, Emmanuel Addo Yobo ${ }^{2}$, David Tenkorang-Twum ${ }^{3}$, Wei Yue ${ }^{4}$, \\ Zhihong Wang ${ }^{5}$ \& Zuxun Lu ${ }^{1 \otimes}$
}

Effective management of dyslipidemia is important. This study aimed to determine the awareness, treatment, control, and determinants of dyslipidemia in middle-aged and older Chinese adults in China. Using data from the 2015 China National Stroke Screening and Prevention Project (CNSSPP), a nationally representative sample of 135,403 Chinese adults aged 40 years or more were included in this analysis. Dyslipidemia was defined by the Third Report of the National Cholesterol Education Program Expert Panel on Detection, Evaluation, and Treatment of High Blood Cholesterol in Adults final report (NCEP-ATP III) and the 2016 Chinese guidelines for the management of dyslipidemia in adults. Models were constructed to adjust for subjects' characteristics with bivariate and multivariable logistic regression analyses. Overall, $51.1 \%$ of the subjects were women. Sixty-four percent were aware of their condition, of whom $18.9 \%$ received treatment, and of whom $7.2 \%$ had adequately controlled dyslipidemia. Dyslipidemia treatment was higher in men from rural areas than their urban counterparts. The multivariable logistic regression models revealed that women, urban residents, and general obesity were positively related to awareness. Women, married respondents, and current drinkers had higher odds of treatment. Age group, overweight, general obesity, urban residence, and women were independent determinants of control. Dyslipidemia awareness rate was moderately high, but treatment and control rates were low. Results can be used to develop policies and health promotion strategies with special focus on middle-aged and older adults.

\author{
Abbreviations \\ CNSSPP China National Stroke Screening and Prevention Project \\ CVD Cardiovascular disease \\ TC Raised total cholesterol \\ TG Raised triglycerides \\ LDL-C Raised low-density lipoprotein \\ HDL-C Low high-density lipoprotein
}

Cardiovascular diseases (CVDs) are the leading cause of morbidity and mortality globally and dyslipidemia is an established risk factor of CVDs such as atherosclerosis ${ }^{1-3}$. Dyslipidemia awareness, treatment, and control have been comprehensively studied among adults. Further, increased awareness, treatment and control of dyslipidemia have contributed to improved primary and secondary prevention of consequent cardiovascular events in developed countries ${ }^{4}$. Yet, the rates of dyslipidemia screening and treatment that have been reported across many lowand middle-income countries vary substantially ${ }^{5}$. China's fast economic development has led to lifestyle changes, including increased tobacco consumption, unhealthy nutrition, and reduced physical activity, which in turn, have led to increased prevalence of dyslipidemia and other CVDs' risk factors in the country ${ }^{6}$. Some previous studies on dyslipidemia among adults in China reported low awareness and management rates. For example, in 2011, Song et al. reported dyslipidemia awareness, treatment, and control rates among Chinese adults as 20.3, 14.4, and $4.9 \%$, respectively ${ }^{7}$. Additionally, a prior national study reported high prevalence rates for total cholesterol

\footnotetext{
${ }^{1}$ Department of Social Medicine and Health Management, School of Public Health, Tongji Medical College, Huazhong University of Science and Technology, No. 13 Hangkong Road, Wuhan 430030, China. ${ }^{2}$ Department of Medicine, SUNY Upstate Medical University, New York, USA. ${ }^{3}$ Department of Adult Health, School of Nursing and Midwifery, University of Ghana, Accra, Ghana. ${ }^{4}$ Department of Neurology, Tianjin Huanhu Hospital, Tianjin, China. ${ }^{5}$ Department of Neurology, Shenzhen Second People's Hospital, Shenzhen University, Shenzhen, Guangdong, China. ${ }^{\varpi}$ email: samblessvissions@gmail.com; luac6@163.com
} 
(TC), low-density lipoprotein (LDL-C), and triglycerides (TG), but low awareness and treatment rates ${ }^{8}$. Further, in 2014, a systematic review on dyslipidemia epidemiology reported the following estimates: prevalence, $42 \%$; awareness, $24.4 \%$; treatment, $8.8 \%$; and control, $4.3 \%{ }^{9}$. With reference to the "rule of halves" framework ${ }^{10}$, it can be observed from the aforementioned results that the rates of dyslipidemia awareness, treatment, and control have been low. The 'rule of halves' is a proxy framework used to estimate indicators of unmet needs for chronic diseases and stipulates that: (1) about $50 \%$ of all diseases should be diagnosed, (2) of whom about $50 \%$ should receive treatment and, (3) of whom about $50 \%$ should achieve treatment targets. Meanwhile, earlier studies have demonstrated that ageing is a recognized lipid-related risk factor of CVDs, and an effective treatment and control of dyslipidemia among adults can help reduce consequent CVDs ${ }^{11,12}$. Additionally, improved awareness and positive lifestyle adoption among individuals with dyslipidemia are essential for effective disease management ${ }^{13}$. Hence, a recent estimate of dyslipidemia awareness and management among Chinese adults is needed to better evaluate the effectiveness of care and inform stakeholders on measures to improve disease management. However, studies on dyslipidemia awareness, treatment, and control and their determinants at the national level in China are limited. Therefore, we aimed to estimate the awareness, treatment, and control of dyslipidemia and their determinants among middle-aged and older Chinese adults using a nationwide survey data.

\section{Methods}

Study population and sampling. This cross-sectional study retrieved data from the 2015 survey of the China National Stroke Screening and Prevention Project (CNSSPP). This project is a nationwide program instituted by the Chinese government in 2011. The survey is conducted annually as a stroke surveillance program in the country. Details have been described elsewhere ${ }^{14}$. In brief, the survey involved Chinese adults aged 40 years or more. It used a two-stage stratified cluster sampling procedure. Firstly, 200 project areas were selected in proportion to the local population size and numbers of total counties. Secondly, an urban community and a rural village were determined as primary sampling units within each project area according to geographical location and suggestions from local hospitals. This cluster sampling method was implemented in each primary sampling unit. All individuals aged 40 years or above were recruited during the primary screening ${ }^{14}$. About 180,000 participants were randomly selected for further assessment for stroke risk factors such as dyslipidemia. Questionnaires completion and assessment were done in primary healthcare facilities.

Data collection. Personnel were trained to collect data from participants using questionnaires. The questionnaires consisted of several domains, including socio-demographics, medical history, and lifestyle information. In this study, age was grouped into four categories: $40-49,50-59,60-69$, and $\geq 70$ years old $)^{15}$. Ethnicity was categorized as 'Han' (majority ethnic group in China), and 'other ethnicities' (respondents who belong to the remaining ethnicities) ${ }^{6}$. Sex was categorized as either male or female, and marital status was grouped as either married or unmarried ${ }^{16}$. Area of residence was classified into urban or rural areas. An urban area was defined with the 12-component study-specific urbanization index. This criterion had been previously validated to capture the degree of urbanization in the study area (reliability across study waves [Cronbach's Alpha]: 0.850.89 ; validity [correlation with official classification]; $0.75-0.78)^{17}$. Educational status was categorized as primary school or below, junior/middle school, senior/middle school, and college or above ${ }^{18}$. Current smoking was defined as smoking at least one cigarette per day in the last 3 months ${ }^{6}$. Current drinking was defined as drinking alcoholic beverages $\geq 1$ per week for more than half a year ${ }^{6}$. Physical activity was defined as engaging in an activity at least three times per week for at least 30 min each episode, or engaging in heavy physical work ${ }^{18}$. Family history of dyslipidemia was defined on the basis of whether the respondent's family (parents and siblings) had been diagnosed by a physician for dyslipidemia ${ }^{19}$.

Two geographical groupings were used to zone participants: (a) the northern and southern zones (according to the Huai River-Qin Mountains Line $)^{20}$, and (b) the stroke and non-stroke belt zones. The stroke belt zone was defined based on stroke incidence in China, i.e., any region containing provinces that met the criteria for a region of high stroke incidence ${ }^{21}$.

Height and weight were measured with subjects in light clothing and not wearing shoes. A stadiometer was used to measure height to the nearest $0.1 \mathrm{~cm}(\mathrm{~cm})$ in a standing position with closed feet, whereas weight was measured to the nearest 0.1 kilograms $(\mathrm{kg})$ using a digital scale in a standing position. The body mass index (BMI) was calculated as the weight in kilograms divided by the height in meters squared $\left(\mathrm{kg} / \mathrm{m}^{2}\right)$ based on China's Ministry of Health criteria ${ }^{22}$. BMI categories included: underweight, $<18.5 \mathrm{~kg} / \mathrm{m}^{2}$; normal weight, $\geq 18.5 \mathrm{~kg} / \mathrm{m}^{2}$ and $<24 \mathrm{~kg} / \mathrm{m}^{2}$; overweight, $\geq 24 \mathrm{~kg} / \mathrm{m}^{2}$ and $<28 \mathrm{~kg} / \mathrm{m}^{2}$; and obesity, $\geq 28 \mathrm{~kg} / \mathrm{m}^{2}$. Waist circumference (WC) was measured at the midpoint between the iliac crest and the lower rib to the nearest $0.1 \mathrm{~cm}$. Central obesity was defined with the cutoffs points for Asians ( $>90 \mathrm{~cm}$ in men and $>80 \mathrm{~cm}$ in women) $)^{23}$.

Laboratory assay. A standardized protocol was used to collect blood samples from participants at all research centers. Blood samples were drawn from subjects' antecubital veins to measure TG, TC, LDL-C, and high-density lipoprotein cholesterol (HDL-C) values. The samples were collected in the morning after an 8-h overnight fast and transported to the same laboratory (Changchun Kingmed Centre for Clinical Laboratory Co Ltd.) under refrigeration, and then stored at $-20^{\circ} \mathrm{C}$.

Criteria for assessment. Dyslipidemia was defined according to the Third Report of the National Cholesterol Education Program (NCEP) Expert Panel on Detection, Evaluation, and Treatment of High Blood Cholesterol in Adults final report (NCEP-ATP III) ${ }^{24}$. This categorization is the same as that of the latest 2016 Chinese guidelines for the prevention and treatment of dyslipidemia in adults ${ }^{25}$. Dyslipidemia was defined as having either or a combination of TG, LDL-C, HDL-C and TC representing $\geq 2.26, \geq 4.14,<1.04$, and $\geq 6.22 \mathrm{mmol} / \mathrm{l}$, 
respectively, or a current use of lipid-modifying medications ${ }^{25}$. Awareness of dyslipidemia was defined as a self-reported physician diagnosis of dyslipidemia or self-reported use of lipid-lowering medications within the population defined as having dyslipidemia. In addition, treatment of dyslipidemia was defined as using prescribed lipid-lowering medications to treat dyslipidemia among participants with dyslipidemia, and control of dyslipidemia was defined as having dyslipidemia and being treated with medications if the individual has $\mathrm{TC}<6.22 \mathrm{mmol} / \mathrm{l}, \mathrm{LDL}-\mathrm{C}<4.14 \mathrm{mmol} / \mathrm{l}, \mathrm{HDL}-\mathrm{C} \geq 1.04 \mathrm{mmol} / \mathrm{l}$ and $\mathrm{TG}<2.26 \mathrm{mmol} / \mathrm{l}^{8,9,22}$.

Data analysis. The International Business Machine Statistical Package for Social Sciences (IBM SPSS) version 19.0 (SPSS Inc, Chicago, Ill) software was used for all analyses. To reduce measurement errors, individuals with missing/incomplete data: BMI $(n=46)$, lipid variables $(n=2519)$, and implausible values of BMI $(<15$ or $\left.>50 \mathrm{~kg} / \mathrm{m}^{2}\right)=876$ were excluded. Again, respondents with no data on lipid-lowering drugs $(41,156)$ were excluded. Hence, 135,403 weighted participants were finally used for the analysis.

Continuous variables were presented as mean \pm standard deviation (SD) for normal distribution, and median and interquartile range (IQR) for skewed distribution. Categorical variables were reported as numbers (percentages), and by proportions and $95 \%$ confidence intervals (CIs). The awareness, treatment, and control rates were standardized to the age- and sex-specific structure of the 2010 Chinese national population census. We explored the associations between determinants (categorical) and the outcome variables of interest (awareness, treatment, and control), using univariate and multivariable logistic models. Data were presented as crude odds ratios (COR) and adjusted odds ratios (AOR) with 95\% CI. All statistical tests were two-tailed and p-values $\leq 0.05$ were considered statistically significant. Processing of graphs and tables was done using Microsoft (MS) excel 2013.

Ethical statement. This study was approved by the Ethics Committee of the Xuanwu Hospital Institutional Review Board, Capital Medical University (Beijing, China), and performed according to the declaration of Helsinki. Informed consent was obtained from all survey participants.

\section{Results}

Participants. Table 1 summarizes the description of participants' characteristics according to their dyslipidemia status. Overall, $51.1 \%$ of subjects were women. The overall mean age \pm SD was $56.6 \pm 9.9$ years. More than one-third of respondents were aged 50-59 years (42.3\%). Approximately three-fifths $(62.1 \%)$ of the subjects had primary or no education, and over 50\% lived in rural areas (53.6\%). Majority of the participants (94.3\%) had a family history of dyslipidemia. Slightly over $40 \%$ of them were overweight, about $33 \%$ were current smokers, $19 \%$ drank alcohol, $62 \%$ were physically active, and about $58 \%$ had central obesity.

Awareness, treatment, and control of dyslipidemia. In this study, we found that, $42.7 \%$ of Chinese adults had dyslipidemia. Among them, $64.0 \%$ were aware of their condition, $18.9 \%$ received treatment, and $7.2 \%$ had adequately controlled dyslipidemia.

Participants aged $\geq 70$ years, and 60-69 years recorded the highest proportion for awareness (64.3\%), and for treatment (19.2\%), respectively. Adequately controlled dyslipidemia was highest among the 40-49 year age group with $(9.8 \%)$. Women compared with men had higher proportion of awareness, treatment, and control (69.2\% vs. $58.3 \%, 23.6 \%$ vs. $12.9 \%$, and $8.3 \%$ vs. $4.7 \%$, respectively; $\mathrm{p}<0.001)$. See Table 2 for further details.

The awareness, treatment, and control of dyslipidemia according to sex and place of residence are shown in Fig. 1. The percentage of dyslipidemia awareness among women in both areas of residence- rural in rural and urban settings was similar ( $\mathrm{p}>0.05)$. Whereas, urban men recorded higher awareness rate compared to their rural counterparts. Treatment was higher in men living in rural compared to urban areas. On the other hand, urban women compared with their rural counterparts had greater treatment rate. Dyslipidemia control was higher in women than in men of both places of residence (all $\mathrm{p}<0.05$ ).

Determinants of awareness, treatment, and control of dyslipidemia. Table 3 shows the CORs and AORs of dyslipidemia determinants. In the multivariable logistic regression analysis, the likelihood of dyslipidemia awareness was higher in women compared with men (AOR 1.14, 95\% CI 1.11-1.18). The results further indicated that urban residents, current drinkers, obese persons, and living in northern China were positively associated with dyslipidemia awareness, and current smokers and living in the stroke belt zone were negatively associated with dyslipidemia awareness $($ all $\mathrm{p}<0.05)$. The awareness of dyslipidemia was more than three times greater in adults with a family history of dyslipidemia in their immediate family compared to those without (AOR 3.91, 95\% CI 3.72-4.01).

Among those who were aware they had dyslipidemia, positive association with treatment was seen among women compared to men, married compared to unmarried respondents, and alcohol drinkers compared to non-drinkers (all $\mathrm{p}<0.05)$.

For subjects who had been treated for dyslipidemia previously, the results showed that women and persons living in northern China were positively associated with dyslipidemia control. Whereas, the probability of control decreased among individuals living in the stroke belt zone and those with more than normal body weight (overweight and obesity). The likelihood of control was 31\% lower in urban compared with rural participants (AOR 0.69, 95\% CI 0.57-0.83). See Table 3 for further details. 


\begin{tabular}{|c|c|c|c|c|}
\hline Variables & Total N(\%) & Dyslipidemia $N(\%)$ & Normal $N(\%)$ & ${ }^{*} p$-value \\
\hline Total & 135,403 & $57,760(42.7)$ & $77,642(57.3)$ & \\
\hline Age (years) & $56.6 \pm 9.9$ & $56.5 \pm 9.7$ & $56.6 \pm 10.2$ & 0.120 \\
\hline \multicolumn{5}{|l|}{ Median (IQR) } \\
\hline $40-49$ & $35,617(26.3)$ & $14,821(25.7)$ & $20,796(26.8)$ & $<0.001$ \\
\hline $50-59$ & $57,300(42.3)$ & $25,037(43.3)$ & $32,263(41.6)$ & \\
\hline $60-69$ & $26,154(19.3)$ & $11,437(19.8)$ & $14,717(19.0)$ & \\
\hline 70 and above & $16,331(12.1)$ & $6465(11.2)$ & $9866(12.7)$ & \\
\hline \multicolumn{5}{|l|}{ Sex } \\
\hline Men & $66,259(48.9)$ & $27,816(48.2)$ & $38,443(49.5)$ & $<0.001$ \\
\hline Women & $69,144(51.1)$ & $29,945(51.8)$ & $39,199(50.5)$ & \\
\hline \multicolumn{5}{|l|}{ Residence } \\
\hline Rural & $72,556(53.6)$ & $31,292(54.2)$ & $41,264(53.1)$ & $<0.001$ \\
\hline Urban & $62,847(46.4)$ & $26,469(45.8)$ & $36,378(46.9)$ & \\
\hline \multicolumn{5}{|l|}{ Nationality } \\
\hline Han & $130,934(96.7)$ & $55,557(96.2)$ & $75,377(97.1)$ & $<0.001$ \\
\hline Others & $4465(3.3)$ & $22.3(3.8)$ & $2262(2.9)$ & \\
\hline \multicolumn{5}{|l|}{ Marital status } \\
\hline Married & $80,154(59.2)$ & $32,362(56.0)$ & $47,792(61.6)$ & $<0.001$ \\
\hline Unmarried & $55,248(40.8)$ & $25,398(44.0)$ & $29,850(38.4)$ & \\
\hline \multicolumn{5}{|l|}{ Level of education } \\
\hline Primary and below & $84,118(62.1)$ & $37,459(64.9)$ & $46,659(60.1)$ & $<0.001$ \\
\hline Junior/Middle School & $32,233(23.8)$ & $12,264(21.2)$ & $19,969(25.7)$ & \\
\hline Senior High School & $13,104(9.7)$ & $5598(9.7)$ & $7506(9.7)$ & \\
\hline College and above & $5948(4.4)$ & $2440(4.2)$ & $3508(4.5)$ & \\
\hline \multicolumn{5}{|l|}{ Geographical regions } \\
\hline North & $75,174(55.5)$ & $29,172(50.5)$ & $46,002(59.2)$ & $<0.001$ \\
\hline South & $60,229(44.5)$ & $28,589(49.5)$ & $31,640(40.8)$ & \\
\hline \multicolumn{5}{|l|}{ Stroke belt zone } \\
\hline Yes & $23,262(17.2)$ & $9449(16.4)$ & $13,813(17.8)$ & $<0.001$ \\
\hline No & $112,142(82.8)$ & $48,312(83.6)$ & $63,830(82.2)$ & \\
\hline Weight & $65.0(58.0-71.5)$ & $65.0(58.0-72.0)$ & $55.0(49.0-63.0)$ & $<0.001$ \\
\hline Height & $162.1 \pm 8.4$ & $161.9 \pm 8.6$ & $162.2 \pm 8.3$ & $<0.001$ \\
\hline \multicolumn{5}{|l|}{ BMI } \\
\hline Median (IQR) & $25.2(23.0-27.5)$ & $25.7(23.5-27.9)$ & $25.1(22.7-27.1)$ & $<0.001$ \\
\hline Underweight $\left(<18.5 \mathrm{~kg} / \mathrm{m}^{2}\right)$ & $46,598(34.4)$ & $16,968(29.4)$ & $29,630(38.2)$ & $<0.001$ \\
\hline Normal $\left(\geq 18.5\right.$ to $\left.<24.0 \mathrm{~kg} / \mathrm{m}^{2}\right)$ & $1835(1.4)$ & $568(1.0)$ & $1267(1.6)$ & \\
\hline Overweight $\left(\geq 24.0\right.$ to $\left.<28 \mathrm{~kg} / \mathrm{m}^{2}\right)$ & $59,314(43.8)$ & $26,232(45.4)$ & $33,082(42.6)$ & \\
\hline Obesity $\left(\geq 28.0 \mathrm{~kg} / \mathrm{m}^{2}\right)$ & $27,655(20.4$ & $13,992(24.2)$ & $13,663(17.6)$ & \\
\hline \multicolumn{5}{|l|}{ Waist circumference $^{\dagger}$} \\
\hline Median (IQR) & $86.0(80.0-93.0)$ & $88.0(80.0-95.0)$ & $85.0(79.0-92.0)$ & $<0.001$ \\
\hline Normal $\leq 90 / 80 \mathrm{~cm}(\mathrm{M} / \mathrm{W})$ & $56,214(42.0)$ & $21,034(36.7)$ & $35,180(45.9)$ & $<0.001$ \\
\hline 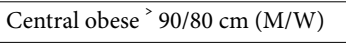 & $77,700(58.0)$ & $36,230(63.3)$ & $41,470(54.1)$ & $<0.001$ \\
\hline Family history of dyslipidemia & $127,624(94.3)$ & $53,695(93.0)$ & $3714(4.8)$ & $<0.001$ \\
\hline Drinking (current) & $25,747(19.0)$ & $11,249(19.5)$ & $14,498(18.7)$ & $<0.001$ \\
\hline Smoking (current) & $43,992(32.5)$ & $19,078(33.0)$ & $24,914(32.1)$ & $<0.001$ \\
\hline Physical activity & $83,913(62.0)$ & $35,349(61.2)$ & $48,564(62.5)$ & $<0.001$ \\
\hline \multicolumn{5}{|c|}{ Blood lipids (mmol/l), median (IQR) } \\
\hline TC & $4.9(4.2-5.6)$ & $5.3(4.4-6.3)$ & $4.7(4.2-5.3)$ & $<0.001$ \\
\hline HDL-C & $1.3(1.1-1.6)$ & $1.1(0.9-1.4)$ & $1.4(1.2-1.7)$ & $<0.001$ \\
\hline LDL-C & $2.9(2.2-3.4)$ & $3.0(2.2-3.9)$ & $2.8(2.2-3.2)$ & $<0.001$ \\
\hline TG & $1.5(1.1-2.2)$ & $2.3(1.5-3.1)$ & $5.5(5.0-6.2)$ & $<0.001$ \\
\hline Non-HDL-C & $3.5(2.8-4.2)$ & $4.1(3.3-4.9)$ & $3.2(2.6-3.8)$ & $<0.001$ \\
\hline
\end{tabular}

Table 1. Participants' characteristics and dyslipidemia status. Dyslipidemia was defined as total cholesterol (TC) $>6.22 \mathrm{mmol} / \mathrm{L}$ or low-density lipoprotein $(\mathrm{LDL}-\mathrm{C})>4.14 \mathrm{mmol} / \mathrm{L}$ or high-density lipoprotein (HDLC) $<1.04 \mathrm{mmol} / \mathrm{L}$ or triglycerides $(\mathrm{TG})>2.26 \mathrm{mmol} / \mathrm{L}$ or non-high density lipoprotein $>4.9 \mathrm{mmol} / \mathrm{L}$ or self-reported treatment. Data shown as mean $\pm \mathrm{SD}$, or median (IQR) or $\mathrm{n}(\%)$. ${ }^{*} p$-value for comparison of dyslipidemia vs. normal subjects. Men (M), Women (W). Unmarried (widowed/divorced/others). 


\begin{tabular}{|c|c|c|c|c|}
\hline \multicolumn{2}{|l|}{ Variable } & Awareness & Treatment & Control \\
\hline \multicolumn{2}{|l|}{ Total } & $36,958(64 \%)$ & $6993(18.9 \%)$ & $504(7.2 \%)$ \\
\hline \multirow{5}{*}{ Age group (years) } & $40-49$ & $64.2(63.4-64.9)$ & $19.1(12.3-27.6)$ & $9.8(5.1-16.8)$ \\
\hline & $50-59$ & $63.7(63.1-64.3)$ & $18.8(12.1-27.3)$ & $6.8(3.1-13.0)$ \\
\hline & $60-69$ & $64.2(63.3-65.1)$ & $19.2(12.4-27.7)$ & $5.2(2.1-10.9)$ \\
\hline & 70 and above & $64.3(63.1-65.4)$ & $18.3(11.7-26.7)$ & $6.6(2.9-12.7)$ \\
\hline & & $\mathrm{p}=0.718$ & $\mathrm{p}=0.632$ & $\mathrm{p}<0.001$ \\
\hline \multirow{3}{*}{ Sex } & Men & $58.3(57.8-58.9)$ & $12.9(7.4-20.5)$ & $4.7(1.8-10.2)$ \\
\hline & Women & $69.2(68.7-69.7)$ & $23.6(16.1-32.6)$ & $8.3(4.1--14.9)$ \\
\hline & & $\mathrm{p}<0.001$ & $\mathrm{p}<0.001$ & $\mathrm{p}<0.001$ \\
\hline \multirow{3}{*}{ Residence } & Rural & $61.0(60.5-61.6)$ & $18.6(11.9-27.1)$ & $8.2(4.0-14.8)$ \\
\hline & Urban & $67.5(66.9-68.1)$ & $19.3(12.5-27.8)$ & $6.2(2.7-12.2)$ \\
\hline & & $\mathrm{p}<0.001$ & $\mathrm{p}=0.081$ & $\mathrm{p}<0.001$ \\
\hline \multirow{3}{*}{ Ethnicity } & Han & $67.5(66.9-68.1)$ & $19.0(12.3-27.5)$ & $7.3(3.4-13.6)$ \\
\hline & Others & $61.0(60.5-61.6)$ & $16.8(10.5-25.0)$ & $4.3(1.5-9.6)$ \\
\hline & & $\mathrm{p}<0.001$ & $\mathrm{p}=0.040$ & $\mathrm{p}=0.077$ \\
\hline \multirow{3}{*}{ Marital Status } & Married & $63.8(63.3-64.3)$ & $19.5(12.7-28.1)$ & $7.0(3.2-13.3)$ \\
\hline & Unmarried & $64.2(63.6-68.2)$ & $18.2(11.6-26.6)$ & $7.5(3.5-13.9)$ \\
\hline & & $\mathrm{p}=0.367$ & $\mathrm{p}<0.001$ & $\mathrm{p}=0.0 .371$ \\
\hline \multirow{5}{*}{ Level of education } & Primary and below & $62.6(62.1-63.1)$ & $18.4(11.8-26.8)$ & $7.3(3.4-13.6)$ \\
\hline & \begin{tabular}{|l|} 
Junior/Middle School \\
\end{tabular} & $65.6(64.8-66.4)$ & $20.1(13.2-28.7)$ & $7.2(3.3-13.5)$ \\
\hline & \begin{tabular}{|l|} 
Senior High School \\
\end{tabular} & $67.0(65.8-69.8)$ & $19.3(12.5-27.8)$ & $6.7(3.0-12.9)$ \\
\hline & College and above & $69.5(67.7-71.3)$ & $19.6(12.7-28.2)$ & $7.2(3.3-13.5)$ \\
\hline & & $\mathrm{p}<0.001$ & $\mathrm{p}=0.001$ & $\mathrm{p}=0.961$ \\
\hline \multirow{3}{*}{ Geographical regions } & North & $63.1(53.4-72.1)$ & $19.5(12.7-28.1)$ & $8.7(4.3-15.4)$ \\
\hline & South & $64.8(55.1-73.6)$ & $18.4(11.8-26.8)$ & $5.6(2.3-11.4)$ \\
\hline & & $\mathrm{p}<0.001$ & $\mathrm{p}=0.009$ & $\mathrm{p}<0.001$ \\
\hline \multirow{3}{*}{ Stroke belt } & Yes & $64.0(54.3-72.9)$ & $18.0(11.4-26.4)$ & $5.0(1.9-10.6)$ \\
\hline & No & $64.8(55.1-73.6)$ & $19.1(12.3-27.6)$ & $7.6(3.6-14.0)$ \\
\hline & & $\mathrm{p}<0.001$ & $\mathrm{p}=0.069$ & $\mathrm{p}=0.003$ \\
\hline \multirow{5}{*}{ BMI } & Underweight $\left(<18.5 \mathrm{~kg} / \mathrm{m}^{2}\right)$ & $64.6(63.9-65.3)$ & $18.3(11.7-26.7)$ & $8.5(4.2-15.2)$ \\
\hline & Normal $\left(\geq 18.5\right.$ to $\left.<24.0 \mathrm{~kg} / \mathrm{m}^{2}\right)$ & $62.1(58.1-66.1)$ & $14.4(8.6-22.3)$ & $7.8(3.7-14.3)$ \\
\hline & Overweight $\left(\geq 24.0\right.$ to $\left.<28 \mathrm{~kg} / \mathrm{m}^{2}\right)$ & $63.6(63.0-64.2)$ & $19.2(12.4-27.7)$ & $6.9(3.1-13.1)$ \\
\hline & Obesity $\left(\geq 28.0 \mathrm{~kg} / \mathrm{m}^{2}\right)$ & $64.0(63.2-64.8)$ & $19.4(12.6-28.0)$ & $6.4(2.8-12.5)$ \\
\hline & & $\mathrm{p}=0.179$ & $\mathrm{p}=0.032$ & $\mathrm{p}=0.075$ \\
\hline \multirow{3}{*}{ Waist circumference } & Normal $\leq 90 / 80 \mathrm{~cm}$ & $62.3(52.6-71.3)$ & $17.7(11.2-26.0)$ & $7.3(3.4-13.6)$ \\
\hline & Central obese' $90 / 80 \mathrm{~cm}$ & $64.9(55.6-73.7)$ & $19.7(12.8-28.3)$ & $7.1(3.3-13.4)$ \\
\hline & & $\mathrm{p}<0.001$ & $\mathrm{p}<0.001$ & $\mathrm{p}<0.001$ \\
\hline \multirow{3}{*}{ Family history of dyslipidemia } & Yes & $66.2(56.6-74.9)$ & $18.9(12.2-27.4)$ & $7.3(3.4-13.6)$ \\
\hline & No & $34.6(25.8-44.3)$ & $19.7(12.8-28.3)$ & $4.3(1.5-9.6)$ \\
\hline & & $\mathrm{p}<0.001$ & $\mathrm{p}=0.438$ & $\mathrm{p}=0.061$ \\
\hline \multirow{3}{*}{ Drinking (current) } & Yes & $68.6(59.1-77.1)$ & $68.6(59.1-77.1)$ & $6.3(2.7-12.3)$ \\
\hline & No & $62.9(53.2-71.9)$ & $62.9(53.2-71.9)$ & $7.6(3.6-14.0)$ \\
\hline & & $\mathrm{p}<0.001$ & $\mathrm{p}<0.001$ & $\mathrm{p}=0.058$ \\
\hline \multirow{3}{*}{ Smoking (current) } & Yes & $68.6(59.1-77.1)$ & $68.6(59.1-77.1)$ & $7.6(3.6-14.0)$ \\
\hline & No & $61.7(51.9-70.8)$ & $61.7(51.9-70.8)$ & $6.9(3.1-13.1)$ \\
\hline & & $\mathrm{p}<0.001$ & $\mathrm{p}<0.001$ & $\mathrm{p}=0.279$ \\
\hline \multirow{3}{*}{ Physical activity } & Yes & $64.1(54.4-73.0)$ & $64.1(54.4-73.0)$ & $7.6(3.6-14.0)$ \\
\hline & No & $63.8(54.1-72.7)$ & $63.8(54.1-72.7)$ & $6.6(2.9-12.7)$ \\
\hline & & $\mathrm{p}=0.370$ & $\mathrm{p}=0.370$ & $\mathrm{p}=0.100$ \\
\hline
\end{tabular}

Table 2. Awareness, treatment, and control of dyslipidemia among subjects. Proportion in each column has been calculated using the values in previous column as a denominator, unmarried (widowed/divorced/others). 


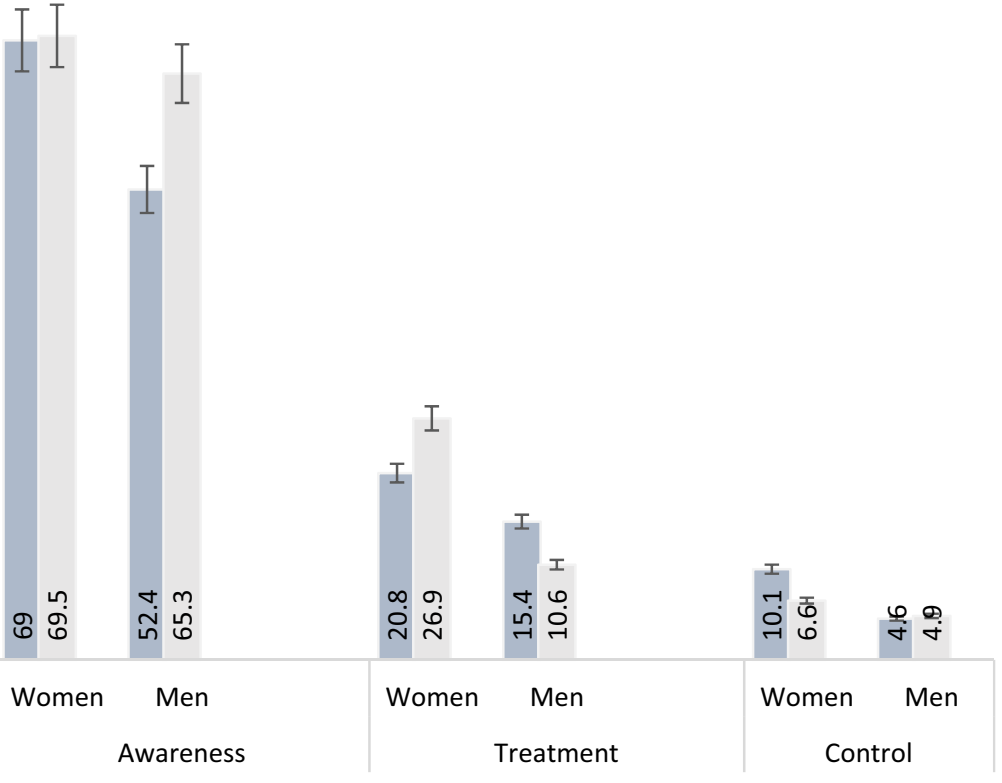

Outcome variables

nural Urban $=$ Overall

Figure 1. The overall, sex and rural/urban proportions of dyslipidemia awareness, treatment and control among the study population.

\section{Discussion}

This study estimated the awareness, treatment, and control of dyslipidemia and their determinants among middle-aged and older Chinese adults using a nationwide survey data. Our findings revealed that $64 \%$ of the subjects had dyslipidemia, of whom $18.9 \%$ received treatment, and of whom $7.2 \%$ had adequately controlled lipids. Treatment and control rates in both places of residence were higher in women than in men. The multivariable analysis revealed that women, urban residents, positive family history of dyslipidemia, current drinking, and general obesity had increased odds of awareness. In addition, women, married respondents, and current drinkers had higher odds of treatment. Age group, overweight, general obesity, stroke belt zone, urban residence, and women were independent determinants of control.

"The rule of halves" framework ${ }^{10}$ suggests that almost $50 \%$ of patients should be aware of their disease, of whom about $50 \%$ should receive treatment, and of whom about $50 \%$ achieve should treatment targets. In the case of our respondents, $64 \%$ were aware of their disease status, which suggests desirable level of awareness. Yet, the treatment $(18.9 \%)$ and control $(7.2 \%)$ rates were far below expected levels. However, compared with some previous reports, the current findings demonstrated improvements in dyslipidemia awareness, treatment, and control rates in China ${ }^{9,26,27}$. The significance of the present study has been emphasized by the low treatment and control rates found. These low rates may signify some gaps and shortcomings such as poor adherence to medications ${ }^{28}$, and drug prescription challenge ${ }^{29,30}$ associated with the current dyslipidemia management strategy. These findings may also support the speculation that providers were not very effective at targeting treatment to goal. Thus, a comprehensive dyslipidemia management approach needs to be emphasized. In addition to the use of pharmacological approach, it is essential to focus on all strategies embedded in the levels of prevention, including targeted and opportunistic screenings, health promotion programs on lifestyle modifications and good nutrition for effective and efficient management as drug therapy alone does not control dyslipidemia completely.

In the present study, subjects aged 40-49 years had higher odds of dyslipidemia control compared with their older counterparts. This result is partly similar to a Korean study where younger adults were more likely to have controlled LDL-C ${ }^{31}$. However, many contradictory results have been reported ${ }^{8,26,29,32}$. Our results may support the finding that control rates of dyslipidemias such as raised TC may differ depending on certain participants' characteristics and country of origin, and rates may range from 18 to $100 \%{ }^{33}$.

Consistent with prior reports ${ }^{26,29}$, our study found that women were more likely to be aware of and treated for dyslipidemia, and they were more likely to have their condition adequately controlled compared to men. Similarly, two studies on the management of raised LDL-C recorded higher likelihood of awareness, treatment, and control among women ${ }^{4,34}$. Behavioral differences between the sexes could partly explain this result, as women are known to seek healthcare services more often than men ${ }^{4}$. Hence, we suggest that men should be considered as a special group of interest in dyslipidemia management in this country.

In line with our results, an earlier study ${ }^{19}$ demonstrated a positive relationship between dyslipidemia awareness and urban residence. Similarly, a study in Thailand found high awareness rate for raised LDL-C among urban residents ${ }^{35}$. Further, a couple of findings from low- and middle-income countries reported lower dyslipidemia 


\begin{tabular}{|c|c|c|c|c|c|c|c|c|}
\hline \multirow{2}{*}{\multicolumn{3}{|c|}{ Variable }} & \multicolumn{2}{|l|}{ Awareness } & \multicolumn{2}{|l|}{ Treatment } & \multicolumn{2}{|l|}{ Control } \\
\hline & & & \multirow{2}{*}{$\begin{array}{l}\text { COR (95\% CI) } \\
0.98(0.94-1.02)\end{array}$} & \multirow[t]{2}{*}{ AOR $(95 \% \mathrm{CI})^{\mathrm{a}}$} & \multirow{2}{*}{$\begin{array}{l}\text { COR }(95 \% \text { CI }) \\
0.99(0.94-1.05)\end{array}$} & \multirow[t]{2}{*}{ AOR $(95 \% \mathrm{CI})^{\mathrm{a}}$} & \multirow{2}{*}{$\begin{array}{l}\text { COR }(95 \% \text { CI) } \\
0.67(0.54-0.82)\end{array}$} & \multirow{2}{*}{\begin{tabular}{|c|} 
AOR $(95 \% \text { CI })^{\mathrm{a}}$ \\
$0.69(0.55-0.85)$
\end{tabular}} \\
\hline \multirow{3}{*}{ Age } & & $50-59$ & & & & & & \\
\hline & (Ref: 40-49) & $60-69$ & $1.00(0.95-1.05)$ & & $1.02(0.96-1.09)$ & & $0.51(0.38-0.67)$ & $0.54(0.40-0.71)$ \\
\hline & & 70 and above & $1.00(0.94-1.07)$ & & $0.98(0.91-1.06)$ & & $0.64(0.47-0.89)$ & $0.68(0.49-0.95)$ \\
\hline Sex & (Ref: men) & & $1.61(1.55-1.66)$ & $1.14(1.11-1.18)$ & $1.89(1.81-1.97)$ & $2.01(1.88-2.15)$ & $1.83(1.46-2.29)$ & $1.73(1.37-2.18)$ \\
\hline Residence & (Ref: rural) & & $1.33(1.28-1.37)$ & $1.15(1.12-1.18)$ & $1.00(0.96-1.05)$ & & $0.74(0.62-0.89)$ & $0.69(0.57-0.83)$ \\
\hline Nationality & (Ref: others) & & $1.07(0.95-1.13)$ & & $1.07(0.96-1.20)$ & & $1.74(0.92-3.28)$ & \\
\hline Marital Status & (Ref: unmarried) & & $0.98(0.95-1.02)$ & & $1.06(1.02-1.11)$ & $1.07(1.01-1.13)$ & $0.92(0.77-1.10)$ & \\
\hline \multirow{3}{*}{ Level of Education } & & $\begin{array}{l}\text { Junior/Middle } \\
\text { School }\end{array}$ & $1.14(1.09-1.19)$ & $0.99(0.96-1.01)$ & $1.10(1.04-1.16)$ & $1.03(0.96-1.10)$ & $0.98(0.79-1.22)$ & \\
\hline & $\begin{array}{l}\text { (Ref: primary and } \\
\text { below) }\end{array}$ & Senior High School & $1.21(1.14-1.29)$ & $0.97(0.93-1.01)$ & $1.07(1.00-1.15)$ & $0.98(0.89-1.07)$ & $0.92(0.67-1.25)$ & \\
\hline & & College and above & $1.36(1.25-1.49)$ & $1.02(0.96-1.09)$ & $1.15(1.03-1.27)$ & $0.92(0.81-1.06)$ & $0.99(0.64-1.52)$ & \\
\hline $\begin{array}{l}\text { Geographical } \\
\text { regions }\end{array}$ & (Ref: South) & & $0.93(0.90-0.96)$ & $1.05(1.02-1.08)$ & $1.02(0.98-1.06)$ & & $1.59(1.32-1.92)$ & $1.91(1.57-2.32)$ \\
\hline Stroke belt & $\begin{array}{l}\text { (Ref: Non-stroke } \\
\text { belt) }\end{array}$ & & $0.80(0.77-0.84)$ & $0.85(0.83-0.88)$ & $0.91(0.86-0.97)$ & $0.93(0.87-1.01)$ & $0.64(0.47-0.86)$ & $0.52(0.38-0.71)$ \\
\hline \multirow{3}{*}{ BMI } & & $\begin{array}{l}\text { Underweight } \\
\left(<18.5 \mathrm{~kg} / \mathrm{m}^{2}\right)\end{array}$ & $0.90(0.76-1.07)$ & $0.94(0.85-1.04)$ & $0.84(0.67-1.06)$ & $0.78(0.58-1.01)$ & $0.94(0.34-2.62)$ & $1.21(0.43-3.43)$ \\
\hline & $\begin{array}{l}\text { (Ref: Normal } \\
(\geq 18.5-<24.0 \mathrm{~kg} / \\
\left.\mathrm{m}^{2}\right)\end{array}$ & $\begin{array}{l}\text { Overweight } \\
\left(\geq 24.0-<28 \mathrm{~kg} / \mathrm{m}^{2}\right)\end{array}$ & $0.96(0.92-0.99)$ & $1.00(0.97-1.03)$ & $1.07(1.02-1.13)$ & $1.03(0.96-1.10)$ & $0.80(0.65-0.99)$ & $0.79(0.64-0.96)$ \\
\hline & & $\begin{array}{l}\text { Obesity }(\geq 28.0 \mathrm{~kg} / \\
\left.\mathrm{m}^{2}\right)\end{array}$ & $0.98(0.93-1.02)$ & $1.04(1.00-1.07)$ & $1.09(1.03-1.15)$ & $1.06(0.98-1.14)$ & $0.74(0.58-0.95)$ & $0.74(0.58-0.95)$ \\
\hline $\begin{array}{l}\text { Waist circumfer- } \\
\text { ence }\end{array}$ & $\begin{array}{l}\text { (Ref: Nor- } \\
\mathrm{mal} \leq 90 / 80 \mathrm{~cm})\end{array}$ & & $1.12(1.08-1.16)$ & $1.01(0.98-1.03)$ & $1.15(1.10-1.20)$ & $0.96(0.90-1.02)$ & $0.96(0.80-1.17)$ & \\
\hline $\begin{array}{l}\text { Family history of } \\
\text { dyslipidemia }\end{array}$ & (Ref: no) & & $3.71(3.47-3.97)$ & $3.91(3.72-4.01)$ & $0.94(0.87-1.02)$ & & $1.67(0.94-2.98)$ & \\
\hline Drinking (current) & (Ref: no) & & $1.29(1.24-1.35)$ & $1.06(1.03-1.10)$ & $1.53(1.46-1.61)$ & $1.18(1.10-1.26)$ & $0.81(0.66-1.01)$ & \\
\hline Smoking (current) & (Ref: no) & & $1.36(1.31-1.41)$ & $0.95(0.92-0.98)$ & $1.42(1.36-1.48)$ & $0.96(0.90-1.02)$ & $1.11(0.92-1.33)$ & \\
\hline Physical activity & (Ref: no) & & $1.02(0.98-1.05)$ & & $1.02(0.98-1.07)$ & & $1.17(0.97-1.42)$ & \\
\hline
\end{tabular}

Table 3. Univariate and multivariable analyses of factors affecting awareness, treatment, and control of dyslipidemia among adults. COR Crude odds ratio, $A O R$ adjusted odds ratio, $C I$ confidence interval.

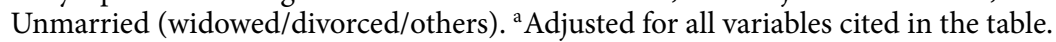

awareness and treatment rates in rural settings ${ }^{22,36}$. The high level of awareness found in urban areas in the present study may be attributed to the wealthier and better educated populations usually found in cities and municipalities ${ }^{37}$. Again, it may buttress the evidence of difficult access to health care common in rural areas ${ }^{13}$. So, health promotion programs should target deprived areas with limited resources. Surprisingly, lower level of dyslipidemia control was seen among urban subjects.

The result of our study shows that married persons were more likely to receive treatment for their condition. This finding is in line with another study on the treatment of hypertension ${ }^{38}$. According to the social causation theory, individuals could benefit from spousal support ${ }^{39}$. For example, living together allows quicker appreciation and response to threatening signals. Again, spouses, mostly wives, usually encourage the adoption of healthy behavior such as a healthy lifestyle and adherence to treatment that may promote cardiovascular health ${ }^{40}$.

From this study, staying in northern China was an independent determinant of dyslipidemia awareness and control. A previous study indicated that stroke prevalence was significantly higher in the northern parts of China ${ }^{20}$, and living in the north was associated with high prevalence of dyslipidemia ${ }^{7,41}$. We speculate that the high prevalence of stroke and dyslipidemia found in the north could positively affect inhabitants' behaviors towards treatment and result in favorable outcomes.

The role of geographic determinants in CVD risk factors' control is essential for developing effective population-wide clinical and preventive strategies ${ }^{42}$. In the current study, individuals living in the stroke belt zone had lower likelihood of dyslipidemia control. This is inconsistent with the results of the Geographic and Racial Differences in Stroke (REGARDS) study, which reported lower likelihood of dyslipidemia control outside the stroke belt zone ${ }^{43}$. The reason for the current finding could be that effective and efficient management of lipid disorders may not be related to the stroke belt zone. Further studies are required to investigate why control of dyslipidemia were less likely in the stroke belt zone.

We observed a positive association between dyslipidemia awareness and general obesity. This is consistent with an earlier study ${ }^{19}$, but contrary to another report ${ }^{44}$. In addition, dyslipidemia awareness relates to weight management. It has been noted that awareness can improve weight perception and management since obesity is a risk factor of dyslipidemia and weight loss has beneficial effects on dyslipidemia prevention and control ${ }^{45}$. Also, we found general obesity as a significant negative predictor of dyslipidemia control, which is similar to earlier findings ${ }^{8,19}$. A probable explanation could be that dyslipidemia control is difficult in individuals with more than normal body weight. 
Persons with a family history of dyslipidemia in their immediate family had the strongest independent association of awareness in this study. This is in line with the result of He et al. ${ }^{8}$, where persons with a family history of dyslipidemia had higher likelihood of awareness. Predictably, family members would be more mindful and watchful of the condition and doctors would pay more attention to these patients. This study found that current drinking was positively associated with dyslipidemia awareness and treatment. This was dissimilar to a study in the Jilin Province ${ }^{8}$. The reason for the current finding could be that individuals with dyslipidemia who are alcohol drinkers might usually receive counselling on drinking cessation and treatment from physicians or other health workers, so they are more likely to be aware and treated for lipid disorders. Current smokers were less likely to get their condition treated in the current study. This is in accordance with an earlier report in China ${ }^{8}$. This result could mean that smokers don't pay enough attention to their healthcare ${ }^{46}$.

Strengths and limitations. Key strengths of the study include its population-based design, representative of various urban and rural communities across China. Thus, the nationwide coverage allows for calculation of nationally representative estimates. Further, the analysis consisted of many determinants of dyslipidemia awareness, treatment, and control, which may provide a broader view of the relative role of different determinants in prevention efforts.

This survey was cross-sectional; thus, the opportunity to explore casualty was limited. Another limitation observed was that participants' previous experience with medication use for other conditions could affect treatment adherence. Also, we did not investigate the effect of cognitive factors such as self-efficacy and illness perception of people who received treatment and had controlled dyslipidemia. Information bias might occur from self-reported characteristics.

\section{Conclusion}

In summary, we found high dyslipidemia awareness rate, with low treatment and control rates. Higher proportions of awareness, treatment, and control were noted in women than in men. Treatment rate was higher in rural than urban men, but women in urban areas showed higher treatment rate compared with their rural counterparts. Dyslipidemia control rate was greater in women than men in both rural and urban areas.

Women, urban residence, positive family history of dyslipidemia, and general obesity were positively associated with awareness. Married respondents, women, and current drinkers were more likely to be treated for dyslipidemia. Age groups, general obesity, women, urban residence, and overweight had significant relationship with control. Therefore, improved health education and treatment are needed for better dyslipidemia management.

Received: 17 August 2020; Accepted: 26 April 2021

Published online: 12 May 2021

\section{References}

1. Rosamond, W. et al. Heart disease and stroke statistics-2007 update: A report from the American Heart Association Statistics Committee and Stroke Statistics Subcommittee. Circulation 115, e69-171. https://doi.org/10.1161/circulationaha.106.179918 (2007).

2. McQueen, M. J. et al. Lipids, lipoproteins, and apolipoproteins as risk markers of myocardial infarction in 52 countries (the INTERHEART study): A case-control study. Lancet (London, England) 372, 224-233. https://doi.org/10.1016/s0140-6736(08) 61076-4 (2008).

3. Disease, C. \& Management, R. Standards of medical care in diabetes-2019. Diabetes Care 42, S103-S123. https://doi.org/10.2337/ dc19-S010 (2019).

4. Goff, D. C. Jr. et al. Dyslipidemia prevalence, treatment, and control in the Multi-Ethnic Study of Atherosclerosis (MESA): Gender, ethnicity, and coronary artery calcium. Circulation 113, 647-656. https://doi.org/10.1161/circulationaha.105.552737 (2006).

5. Farzadfar, F. et al. National, regional, and global trends in serum total cholesterol since 1980: Systematic analysis of health examination surveys and epidemiological studies with 321 country-years and 3.0 million participants. Lancet (London, England) 377, 578-586. https://doi.org/10.1016/s0140-6736(10)62038-7 (2011).

6. Opoku, S. et al. Prevalence and risk factors for dyslipidemia among adults in rural and urban China: Findings from the China National Stroke Screening and prevention project (CNSSPP). BMC Public Health 19, 1500. https://doi.org/10.1186/s12889-0197827-5 (2019).

7. He, H. et al. Dyslipidemia awareness, treatment, control and influence factors among adults in the Jilin province in China: A cross-sectional study. Lipids Health Dis. 13, 122. https://doi.org/10.1186/1476-511x-13-122 (2014).

8. Song, P. et al. Socioeconomic and geographic variations in the prevalence, awareness, treatment and control of dyslipidemia in middle-aged and older Chinese. Atherosclerosis 282, 57-66. https://doi.org/10.1016/j.atherosclerosis.2019.01.005 (2019).

9. Huang, Y., Gao, L., Xie, X. \& Tan, S. C. Epidemiology of dyslipidemia in Chinese adults: Meta-analysis of prevalence, awareness, treatment, and control. Popul. Health Metr. 12, 28. https://doi.org/10.1186/s12963-014-0028-7 (2014).

10. Hart, J. T. Rule of halves: Implications of increasing diagnosis and reducing dropout for future workload and prescribing costs in primary care. Br. J. Gen. Pract. 42, 116-119 (1992).

11. Nelson, R. H. Hyperlipidemia as a risk factor for cardiovascular disease. Prim. Care 40, 195-211. https://doi.org/10.1016/j.pop. 2012.11.003 (2013).

12. Einarson, T. R., Acs, A., Ludwig, C. \& Panton, U. H. Prevalence of cardiovascular disease in type 2 diabetes: A systematic literature review of scientific evidence from across the world in 2007-2017. Cardiovasc. Diabetol. 17, 83. https://doi.org/10.1186/s12933018-0728-6 (2018).

13. Janus, E. D. et al. Dyslipidaemia in rural Australia: Prevalence, awareness, and adherence to treatment guidelines in the Greater Green Triangle Risk Factor Study. Med. J. Aust. 192, 127-132 (2010).

14. Wang, X. et al. Carotid atherosclerosis detected by ultrasonography: A National cross-sectional study. J. Am. Heart Assoc. https:// doi.org/10.1161/jaha.118.008701 (2018).

15. Yan, S. et al. The expanding burden of cardiometabolic risk in China: The China Health and Nutrition Survey. Obes. Rev. 13, 810-821. https://doi.org/10.1111/j.1467-789X.2012.01016.x (2012).

16. Wang, Y. et al. Sex differences in the association between marital status and the risk of cardiovascular, cancer, and all-cause mortality: A systematic review and meta-analysis of 7,881,040 individuals. Glob. Health Res. Policy 5, 4. https://doi.org/10.1186/ s41256-020-00133-8 (2020). 
17. Jones-Smith, J. C. \& Popkin, B. M. Understanding community context and adult health changes in China: Development of an urbanicity scale. Soc. Sci. Med. 71, 1436-1446. https://doi.org/10.1016/j.socscimed.2010.07.027 (2010).

18. Gan, Y. et al. Prevalence and risk factors associated with stroke in middle-aged and older Chinese: A community-based crosssectional study. Sci. Rep. 7, 9501. https://doi.org/10.1038/s41598-017-09849-z (2017).

19. Zhang, F.-L. et al. The prevalence, awareness, treatment, and control of dyslipidemia in northeast China: A population-based cross-sectional survey. Lipids Health Dis. 16, 61. https://doi.org/10.1186/s12944-017-0453-2 (2017).

20. Li, Q. et al. Prevalence of stroke and vascular risk factors in China: A nationwide community-based study. Sci. Rep. 7, 6402. https:// doi.org/10.1038/s41598-017-06691-1 (2017).

21. Xu, G., Ma, M., Liu, X. \& Hankey, G. J. Is there a stroke belt in China and why?. Stroke 44, 1775-1783. https://doi.org/10.1161/ strokeaha.113.001238 (2013).

22. Pan, L. et al. The prevalence, awareness, treatment and control of dyslipidemia among adults in China. Atherosclerosis 248, 2-9. https://doi.org/10.1016/j.atherosclerosis.2016.02.006 (2016).

23. Ahmad, N., Adam, S. I. M., Nawi, A. M., Hassan, M. R. \& Ghazi, H. F. Abdominal obesity indicators: Waist circumference or waist-to-hip ratio in Malaysian adults population. Int. J. Prev. Med. 7, 82-82. https://doi.org/10.4103/2008-7802.183654 (2016).

24. Expert Panel on Detection, Evaluation, and Treatment of High Blood Cholesterol in Adults. Executive summary of the third report of the national cholesterol education program (NCEP) expert panel on detection, evaluation, and treatment of high blood cholesterol in adults (adult treatment panel III). JAMA 285(19), 2486-2497. https://doi.org/10.1001/jama.285.19.2486 (2001).

25. Joint Committee for Guideline. Chinese guidelines for the management of dyslipidemia in adults. J. Geriatr. Cardiol. 15(1-29), 2018. https://doi.org/10.11909/j.issn.1671-5411.2018.01.011 (2016).

26. Liu, X. et al. Dyslipidemia prevalence, awareness, treatment, control, and risk factors in Chinese rural population: The Henan rural cohort study. Lipids Health Dis. 17, 119. https://doi.org/10.1186/s12944-018-0768-7 (2018).

27. Yang, W. et al. Serum lipids and lipoproteins in Chinese men and women. Circulation 125, 2212-2221. https://doi.org/10.1161/ circulationaha.111.065904 (2012).

28. Brown, M. T. \& Bussell, J. K. Medication adherence: WHO cares?. Mayo Clin. Proc. 86, 304-314. https://doi.org/10.4065/mcp. 2010.0575 (2011).

29. Cai, L., Zhang, L., Liu, A., Li, S. \& Wang, P. Prevalence, awareness, treatment, and control of dyslipidemia among adults in Beijing, China. J. Atheroscler. Thromb. 19, 159-168. https://doi.org/10.5551/jat.10116 (2012).

30. Gould, A. L., Davies, G. M., Alemao, E., Yin, D. D. \& Cook, J. R. Cholesterol reduction yields clinical benefits: Meta-analysis including recent trials. Clin. Ther. 29, 778-794. https://doi.org/10.1016/j.clinthera.2007.05.012 (2007).

31. Lee, Y. H. et al. Serum cholesterol concentration and prevalence, awareness, treatment, and control of high low-density lipoprotein cholesterol in the Korea National Health and Nutrition Examination Surveys 2008-2010: Beyond the Tip of the Iceberg. J. Am. Heart Assoc. 3, e000650. https://doi.org/10.1161/jaha.113.000650 (2014).

32. Egan, B. M. et al. Cholesterol control among uninsured adults did not improve from 2001-2004 to 2009-2012 as disparities with both publicly and privately insured adults doubled. J. Am. Heart Assoc. https://doi.org/10.1161/jaha.117.006105 (2017).

33. Tolonen, H., Keil, U., Ferrario, M. \& Evans, A. Prevalence, awareness and treatment of hypercholesterolaemia in 32 populations: Results from the WHO MONICA Project. Int. J. Epidemiol. 34, 181-192. https://doi.org/10.1093/ije/dyi056 (2005).

34. Lotufo, P. A. et al. Prevalence, awareness, treatment, and control of high low-density lipoprotein cholesterol in Brazil: Baseline of the Brazilian Longitudinal Study of Adult Health (ELSA-Brasil). J. Clin. Lipidol. 10, 568-576. https://doi.org/10.1016/j.jacl.2015. 12.029 (2016)

35. Aekplakorn, W. et al. Prevalence of dyslipidemia and management in the Thai population, National Health Examination Survey IV, 2009. J. Lipids 249584-249584, 2014. https://doi.org/10.1155/2014/249584 (2014).

36. Joshi, S. R. et al. Prevalence of dyslipidemia in urban and rural India: The ICMR-INDIAB study. PLoS ONE 9, e96808. https://doi. org/10.1371/journal.pone.0096808 (2014).

37. Supiyev, A. et al. Prevalence, awareness, treatment and control of dyslipidemia in older persons in urban and rural population in the Astana region, Kazakhstan. BMC Public Health 17, 651-651. https://doi.org/10.1186/s12889-017-4629-5 (2017).

38. Kim, J.-S. \& Kim, C.-G. Gender differences in hypertension treatment and control in young adults. J. Nurs. Res. 28, e88 (2020).

39. Fournier, S., Muller, O., Ludman, A. J., Lauriers, N. \& Eeckhout, E. Influence of socioeconomic factors on delays, management and outcome amongst patients with acute myocardial infarction undergoing primary percutaneous coronary intervention. Swiss. Med. Wkly. 143, w13817. https://doi.org/10.4414/smw.2013.13817 (2013).

40. Kilpi, F., Konttinen, H., Silventoinen, K. \& Martikainen, P. Living arrangements as determinants of myocardial infarction incidence and survival: A prospective register study of over 300,000 Finnish men and women. Soc. Sci. Med. 133, 93-100. https://doi.org/ 10.1016/j.socscimed.2015.03.054 (2015).

41. Gu, D. et al. Prevalence of cardiovascular disease risk factor clustering among the adult population of China: Results from the International Collaborative Study of Cardiovascular Disease in Asia (InterAsia). Circulation 112, 658-665. https://doi.org/10.1161/ circulationaha.104.515072 (2005).

42. Zweifler, R. M. et al. Racial and geographic differences in prevalence, awareness, treatment and control of dyslipidemia: The reasons for geographic and racial differences in stroke (REGARDS) study. Neuroepidemiology 37, 39-44. https://doi.org/10.1159/00032 8258 (2011).

43. Reiger, S. et al. Awareness, treatment, and control of dyslipidemia in rural South Africa: The HAALSI (Health and Aging in Africa: A Longitudinal Study of an INDEPTH Community in South Africa) study. PLoS ONE 12, e0187347. https://doi.org/10.1371/journ al.pone.0187347 (2017).

44. Fang, K. et al. Weight underestimation for adults in Beijing and its association with chronic disease awareness and weight management. Lipids Health Dis. 17, 225. https://doi.org/10.1186/s12944-018-0873-7 (2018).

45. Fu, Y. et al. Factors associated with dyslipidemia awareness among residents in Beijing: Results from CCEIP. Zhongguo Shiyong Neike Zazhi/Chinese J. Pract. Intern. Med. 30, 38-40 (2010).

46. Agyemang, C., Van Valkengoed, I., Koopmans, R. \& Stronks, K. Factors associated with hypertension awareness, treatment and control among ethnic groups in Amsterdam, the Netherlands: the SUNSET study. J. Hum. Hypertens. 20, 874-881 (2006).

\section{Acknowledgements}

The authors are grateful to all study participants of the CNSSPP, faculty, and colleagues for their contributions in this study.

\section{Author contributions}

S.O. developed the research question and design, and conducted analysis of the manuscript, S.O., Y.G., E.A.Y., W.Y., Z.W., and D.T.T. contributed to the final drafting and critical revision of the manuscript and Z.X.L. approved the final design and provided supervision. All authors have approved the final manuscript. 


\section{Funding}

This study was funded by the Ministry of Finance of the People's Republic of China (Finance and Social Security [2011] Document No. 61, Ministry of Finance). Innovation Committee of Shenzhen Science and Technology (KJYY20170413162318686) funded ZHW. ZXL was funded by the Fundamental Research Funds for the Central Universities, Huazhong University of Science and Technology, Wuhan, China (2016YXMS215). YG was funded by the China Postdoctoral Science Foundation funded project (2018M630870).

\section{Competing interests}

The authors declare no competing interests.

\section{Additional information}

Correspondence and requests for materials should be addressed to S.O. or Z.L.

Reprints and permissions information is available at www.nature.com/reprints.

Publisher's note Springer Nature remains neutral with regard to jurisdictional claims in published maps and institutional affiliations.

(c) (i) Open Access This article is licensed under a Creative Commons Attribution 4.0 International

License, which permits use, sharing, adaptation, distribution and reproduction in any medium or format, as long as you give appropriate credit to the original author(s) and the source, provide a link to the Creative Commons licence, and indicate if changes were made. The images or other third party material in this article are included in the article's Creative Commons licence, unless indicated otherwise in a credit line to the material. If material is not included in the article's Creative Commons licence and your intended use is not permitted by statutory regulation or exceeds the permitted use, you will need to obtain permission directly from the copyright holder. To view a copy of this licence, visit http://creativecommons.org/licenses/by/4.0/.

(C) The Author(s) 2021 